\title{
O BEM-ESTAR DE CÃES NA PRÁTICA HOSPITALAR
}

\author{
Ricardo Osman Gomes Aguiar ${ }^{1}$, Andrea Roberto Bueno Ribeiro², Ana Claudia \\ Balda $^{3}$, Paulo Marcelo Tavares Ribeiro ${ }^{3}$
}

${ }^{1}$ Mestrando do Programa de Mestrado em Saúde e Bem-Estar Animal do Complexo Educacional das Faculdades Metropolitanas Unidas-FMU. email:ricardoosmandogbymyside@gmail.com

${ }^{2}$ Profa. Dra. dos Programas de Mestrado em Saúde Ambiental e em Saúde e BemEstar Animal Complexo Educacional das Faculdades Metropolitanas Unidas-FMU.

${ }^{3}$ Prof. Dr. do Programa de Mestrado em Saúde e Bem-Estar Animal Complexo

Educacional das Faculdades Metropolitanas Unidas-FMU.

Recebido em: 02/10/2017 - Aprovado em: 21/11/2017 - Publicado em: 05/12/2017 DOI: 10.18677/EnciBio_2017B42

\begin{abstract}
Os animais são seres sencientes, com sistemas biológico e psicológico complexos e necessidades específicas que, em conjunto, determinam seu grau de bem-estar. Assim, a prática hospitalar veterinária deve considerar as liberdades, oportunidades e necessidades desses pacientes, respeitando a importância da relação cão-tutor e buscando promover emoções positivas, mitigando as negativas neste ambiente e durante 0 tratamento do paciente canino. Esta abordagem, iniciada com a publicação de Animal Machines, de Ruth Harrison, em 1964, ganhou maior expressão nos últimos anos com o avanço do conhecimento cientifico na área de bem-estar animal, e, para os animais de companhia, em especial, como reflexo do aumento do número destes nos grandes centros, integrado como parte dos membros das famílias humanas. Assim, o bem-estar passa a ser o pilar do tratamento e não o complemento. Desta forma, o objetivo deste estudo foi identificar, por meio de revisão de literatura, os aspectos da fisiologia e do comportamento dos cães, bem como os resultados já publicados, em relação às características do ambiente e da condução do atendimento e internação destes nas clínicas e hospitais veterinários, que influenciam de forma positiva ou negativa seu bem-estar.
\end{abstract}

PALAVRAS-CHAVE: Ciclo circadiano, Estresse canino, Internação canina, Relação cão-tutor.

\section{THE WELFARE OF DOGS IN THE HOSPITALAR PRACTICE}

\begin{abstract}
Animals are sentient beings with complex biological and psychological systems and specific needs that, together, determine their degree of welfare. Therefore, the veterinary hospital practice should consider the freedoms, opportunities and needs of these patients, respecting the importance of the dog-guard relationship and seeking to promote positive emotions, mitigating the negative ones. This approach, begun with the publication of Ruth Harrison's Animal Machines, in 1964, and has received greater expression in recent years, with the advancement of scientific knowledge in animal welfare and in special for pets, with the increase in their population in
\end{abstract}


metropolitan areas, integrating human families as members. Thus, animal welfare becomes the pillar of the treatment, not the complement. The objective of this study was identifying, through a literature review, aspects of the physiology and behavior of dogs, as well as the results already published, regarding the characteristics of the environment and the conduct of care and hospitalization in the clinics and veterinary hospitals, which positively or negatively influence their well-being.

KEYWORDS: Animal welfare. Canine hospitalization. Circadian cycle. Distress in canines.

\section{INTRODUÇÃO}

Os pacientes cães são seres com aspectos físico (Bios), mental (Psyché) e natural (Telos) e devem ser atendidos nos consultórios e nos hospitais veterinários considerando esta totalidade (MALDONADO; GARCIA, 2015). Esta é uma abordagem de bem-estar. O bem-estar animal é a condição fisiológica e psicológica na qual o animal é capaz de adaptar-se comodamente ao entorno, podendo satisfazer suas necessidades básicas e desenvolver suas capacidades conforme a sua natureza biológica (MALDONADO; GARCIA, 2015). De forma semelhante Broom (1986) definiu-o como "o estado de um indivíduo em relação às suas tentativas de se adaptar ao seu meio ambiente" e isso inclui sentimentos e saúde (BROOM; FRASER, 2015).

Para Grandin e Johnson (2010), um programa de bem-estar animal deve estar baseado no sistema emocional cerebral. "As emoções vêm em primeiro lugar. É preciso ir ao cérebro para entender o bem-estar animal" ou seja, o ambiente em que os animais vivem, ou estão, deve ativar as suas emoções positivas tanto quanto possível, e não as negativas mais do que o necessário.

Na prática veterinária, três pontos devem ser levados em consideração, bemestar físico, mental e natural. O bem-estar físico está relacionado com a condição corporal do animal, expressa seu funcionamento biológico e reflete tanto as doenças e o estado nutricional como também os cuidados dispensados a ele [...] (Mc MILLAN, 2005). O bem-estar mental está relacionado com a vida psicológica, expressada nos processos mentais, nas capacidades cognitivas e na consciência. Nesse contexto, os sentimentos que 0 animal experimenta (senciência), especialmente as emoções negativas como medo, angústia, tristeza, aflição, irritação e tédio, afetam a saúde mental e física [...] (Mc MILLAN, 2005). O bem-estar natural está relacionado com a finalidade biológica, com a vida natural do animal e com a oportunidade que tem de expressar seu comportamento natural.

Os veterinários devem ser protagonistas nas ações a favor do bem-estar do paciente, oferecendo a este os estímulos necessários - sensoriais e sociais e as condições ambientais que permitam adequada interação entre tudo que o cerca (MALDONADO; GARCIA, 2015).

São inúmeros os fatores que afetam o bem-estar. $\mathrm{O}$ bem-estar dos animais de companhia pode ser influenciado pelo ambiente ou lugar de permanência do animal, tipo de enfermidade, manejo, estilo de criação, seleção e manipulação genética, adestramento, procedimentos clínicos e cirúrgicos, entre outros. Portanto, manifestações clínicas que ajudam a identificar alterações no grau de bem-estar dos animais, seja individual ou coletivamente, devem ser avaliadas e adequadas (MALDONADO; GARCIA, 2015).

Cães são hoje, parte integrante da família brasileira (FAVARO et al., 2015). O Instituto Brasileiro de Geografia e Estatística (IBGE) divulgou em junho de 2015 os resultados de Pesquisa Nacional de Saúde (PNS), realizada no ano de 2013, e pela 
primeira vez o questionário de inquérito continha perguntas sobre animais de companhia (FAVARO et al., 2015). O número de domicílios do País que tinham pelo menos um cão foi de $44,3 \%$. O resultado aponta o total de 52,2 milhões de cães no Brasil em uma população humana estimada em 201 milhões de habitantes (IBGE, 2013). Assim, as preocupações com o bem-estar no Brasil atendem essa demanda crescente de tutores.

O presente trabalho teve como objetivo identificar, por meio de revisão de literatura, aspectos da fisiologia e do comportamento da espécie canina bem como do ambiente em que estão inseridos e que devem ser considerados para a melhoria do bem-estar destes quando em atendimento ou internados em clinicas e hospitais veterinários. Para isso foram utilizadas bases de dados da área (Lilacs, Pubmed, Scielo e Porta de Periódicos da Capes), bem como outras fontes devidamente citadas, com descritores relacionados à bem-estar animal, fisiologia, comportamento e bioclimatologia de cães, atendimento veterinário e ambiente hospitalar veterinário, sem limitar período de publicação.

\section{As bases do bem-estar animal}

\section{DESENVOLVIMENTO}

Na década de 1960, no Reino Unido, a ativista Ruth Harrison publicou o livro Animal Machines (1964) e evidenciou que os sistemas intensivos de produção desequilibravam o funcionamento biológico do animal, forçando-os a tentar se adaptar a situações que eram difíceis ou impossíveis para eles (HARRISON, 2013). A autora mostrou que os animais devem ser capazes de usar suas habilidades locomotoras para caminhar, nadar ou voar e utilizar seus sentidos, como o de ver, o que não podiam fazer na completa escuridão, tendo a necessidade de mostrar padrões de comportamento que são normais para eles, o que não era possível nos sistemas de criação da época (HARRISON, 1964).

As preocupações levantadas por Harrison no livro levaram o governo do Reino Unido a encomendar estudo a um comitê de especialistas, liderado pelo professor Roger Brambell, sobre o bem-estar dos animais em criações intensivas. $O$ relatório de Brambell, divulgado em Londres, em 1965, é um marco na área de bemestar e afirma que os animais devem ter a liberdade de "levantar-se, deitar-se, virarse, limpar-se e esticar seus membros". Na década seguinte, em 1979, baseado no relatório Brambell, foram elaboradas as "Cinco Liberdades", "uma série de direitos morais mínimos", segundo Bernard Rollin (HARRISON, 2013), e consideradas a base do bem-estar animal, sendo adaptadas até sua atual versão (Farm Animal Welfare Committee - FAWC, 2017), sendo estas:

1. Livre de fome ou de sede pelo pronto acesso à água fresca e a uma dieta para manter a plena saúde e vigor;

2. Livre de desconforto, proporcionando um ambiente apropriado, incluindo abrigo e uma confortável área de descanso;

3. Livre de dor, lesão ou doença por prevenção ou diagnóstico rápido e tratamento;

4. Liberdade de expressar um comportamento normal, proporcionando espaço suficiente, instalações adequadas e companhia de sua espécie;

5. Livre de medo e angústia, assegurando condições e tratamento que evitem sofrimento mental.

Neste mesmo contexto, foram listadas as "Cinco Necessidades", conforme definidas pelo Animal Welfare Act de 2006 (ANIMAL WELFARE ACT, 2006, item 9), do governo britânico: 
1. Necessidade de um meio ambiente apropriado;

2. Necessidade de dieta apropriada;

3. Necessidade de exibir padrões de comportamentos normais;

4. Necessidade de companhia ou de isolamento de outros animais;

5. Necessidade de proteção contra dor, sofrimento, ferimento e doença.

E, em 2012, as Cinco Oportunidades dos animais (YEATES, 2013):

1. Oportunidade de selecionar os aportes nutricionais - por meio de uma dieta que seja preferencialmente selecionada;

2. Oportunidade de controle do ambiente - ao permitir o acesso à motivação;

3. Oportunidade de prazer, desenvolvimento e vitalidade - ao manter e melhorar aportes de benefícios;

4. Oportunidade de expressar seu comportamento normal - fornecendo espaço suficiente, gama adequada de instalações e a companhia de animais da mesma espécie;

5. Oportunidade de interesse e de confiança - oferecendo condições e tratamento que levem a um estado mental prazeroso.

Nesta avaliação de liberdades, necessidades e oportunidades as diferentes áreas relacionam-se em "Cinco domínios", onde um comprometimento dos quatro primeiros domínios influencia o quinto domínio, que refere-se ao estado mental do animal (MELLOR; BEUSOLEIL 2015):

Domínio 1: Nutrição e Hidratação

Domínio 2: Ambiente

Domínio 3: Saúde e Estado Funcional

Domínio 4: Comportamento

Domínio 5: Estado mental

Assim, o bem-estar na prática veterinária de cães deve levar em consideração essas abordagens, avaliando todos os diferentes aspectos que, atuando em conjunto, envolvem o animal. As necessidades biológicas, psicológicas e etológicas dos pacientes animais, que vão além do oferecimento de alimento, água e abrigo e que incluem aspectos relacionados com a capacidade cognitiva do animal (manter sua mente ativa) com suas emoções (negativas e positivas) e sentimentos (como se sente $\mathrm{o}$ animal), devem ser discutidas com os clientes, verificando a possibilidade de satisfação (MALDONADO; GARCIA, 2015).

Portanto, medidas de bem-estar animal entram definitivamente nos protocolos de atendimento. Com os tratamentos cada vez mais avançados oferecidos na medicina veterinária, a necessidade de avaliar não apenas o tratamento em si, mas também as implicações deste para o bem-estar do animal, tornou-se mais evidente (CHRISTIANSEN; FORKMAN, 2007).

$\mathrm{Na}$ medicina veterinária, o conceito de bem-estar animal é muitas vezes equiparado ao estado de saúde, mas é importante fazer a distinção entre o sucesso do tratamento em termos de acesso restrito, ou seja, os aspectos de saúde; e o sucesso em termos mais globais, isto é, como o bem-estar geral do animal é, durante e após o tratamento (CHRISTIANSEN; FORKMAN, 2007). 


\section{A domesticação do cão}

O britânico Charles Darwin pesquisou a origem dos cães domésticos (Canis familiaris). Em seu livro "Variação dos Animais e Plantas sob Domesticação" (DARWIN, 1875), Darwin se perguntou se os cães tinham evoluído a partir de uma única espécie de lobo ou outro animal extinto, ou de um acasalamento incomum, talvez entre um lobo e um chacal. Segundo o autor, a força da seleção natural e artificial é "um potente meio de modificação" e razão das diversas raças de cães. Já em 1859, na publicação "A Origem das Espécies e a Seleção Natural”, Darwin já revelava como ocorriam as modificações nas espécies, o que explica a aproximação de caninos e humanos (DARWIN, 2011).

Assim, segundo 0 autor os ancestrais dos atuais cães domésticos encontraram vantagem adaptativa junto às comunidades humanas e tais características foram passadas para novas gerações. Darwin (2000) demonstrou que padrões de comportamento de uma espécie são características confiáveis e conservadas tanto quanto as formas dos dentes, dos ossos e outras estruturas corporais. Os cães, quando desejam dormir num tapete ou em outra superfície dura, geralmente giram em torno e esfregam o chão com suas patas dianteiras numa atitude sem sentido, como se quisessem pisotear a grama e cavar um buraco, da mesma forma que seus ancestrais selvagens certamente faziam quando viviam nas amplas pradarias ou bosques.

Os laços estreitos que unem o cão ao homem têm origem há milhares de anos. Alguns autores citam o surgimento do cão doméstico por volta de 12 mil anos atrás (AXELSSON et al. 2013), Mas para outros, a data é mais antiga, segundo Skoglund et al. (2015) os antepassados do cão divergiram dos ancestrais dos lobos modernos há, pelo menos, 27 mil anos. Segundo Grandin e Johnson (2010) "Os cães são muito diferentes de vários outros animais com os quais trabalhamos porque são hipersociais e hipersensíveis a tudo o que fazemos", assim, o estado natural dos cães é viver com os humanos.

Análises genéticas confirmaram na década de 1990 que os cães têm como parente próximo os lobos cinzentos (Canis lupus). Os dois compartilham $99,9 \%$ de DNA. Em 1977, os cientistas descobriram um filhote de cachorro enterrado nos braços de um ser humano sob uma casa de 12 mil anos de idade, no norte de Israel, sugerindo que os cães foram domesticados no Oriente Médio, pouco antes de as pessoas dominarem a agricultura. Investigações genéticas recentes põe a data da domesticação ainda mais longe (GRIMM, 2015).

Segundo Grimm (2015) os primeiros seres humanos deixaram pilhas de cadáveres nas bordas de seus acampamentos, que foram vistos como verdadeiro banquete, e os lobos se aproximaram. Esses lobos sobreviveram mais tempo e produziram mais filhotes, um processo que, de geração em geração, rendeu animais cada vez mais ousados, até que finalmente um lobo estava comendo nas mãos de uma pessoa. Percebendo a utilidade destes animais, iniciou-se uma segunda fase, mais ativa de domesticação.

Apesar de humanos e cães existirem em ramos diferentes da árvore evolucionária, ambos podem ter adquirido tolerância uns em relação aos outros, devido a alterações nos sistemas neurais que mediam o sentimento de amor pelos filhos (NAGASAWA et al., 2015). Cães podem distinguir indivíduos humanos. Além disso, cães demonstram comportamento diferente em relação aos seus cuidadores, quando comparados a lobos criados por humanos, e a interação com cães provoca nos humanos um efeito de proteção social (NAGASAWA et al., 2015).

A origem da convivência de cães e de gatos com os humanos é distinta. Os 
humanos primitivos precisavam dos cães para guardar seus povoados e ajudá-los na caça, e os cachorros primitivos necessitavam dos humanos para ter comida e abrigo. Dependiam um do outro. Com pessoas e gatos, era um relacionamento de convivência. Os gatos matavam os ratos e os humanos forneciam os ratos, que viviam nos povoados. As duas espécies não precisavam tanto uma da outra, apenas aproveitavam de uma proximidade (GRANDIN; JOHNSON, 2010).

\section{Hospital e atendimento veterinário}

Clínicas e hospitais veterinários podem desenvolver um programa específico para o bem-estar de seus pacientes caninos e felinos (JERICÓ et al., 2015). Um programa deste tipo implica em reconhecer e trabalhar por um serviço veterinário centrado no vínculo humano-animal que se constrói diariamente entre o clínico, o tutor e o animal (MALDONADO; GARCIA, 2015). Para os autores, é fundamental aceitar que a principal responsabilidade do clínico veterinário é conseguir a saúde física, mental e natural dos animais sob seus cuidados, bem como a satisfação das necessidades de todos os que participam dessa relação, possibilitando humanizar o serviço e melhorar a qualidade de vida de todos.

Um programa de bem-estar para pequenos animais inclui os aspectos tradicionais de cuidados veterinários com ênfase na promoção da saúde no sentido mais positivo, incorporando a percepção subjetiva de elementos como o sofrimento e a qualidade de vida do animal. Trata-se de um processo de caráter histórico no qual se deve ter em consideração, além das manifestações clínicas, diagnóstico, taxas de prevalência e incidência e os fatores de risco, os fatores sociais, culturais e psicoafetivos de cada grupo humano onde vivem os animais (MALDONADO; GARCIA, 2015).

Maldonado e Garcia (2015) ressaltam que interpretar os estados emocionais e motivacionais dos pacientes é fundamental. Em nível mental, o médico-veterinário necessita desenvolver capacidades e habilidades para reconhecer a linguagem e os sinais de comunicação dos cães e dos gatos, suas expressões faciais, suas posturas corporais e suas vocalizações, as quais serão fundamentais para identificar e interpretar os estados emocionais e motivacionais que os pacientes experimentam. Em nível comportamental, muitos sinais e sintomas têm estreita correlação com os estados emocionais do paciente e são claros indicadores de distúrbios comportamentais, como taquipnéia, taquicardia, midríase, vômito, salivação, defecção e micção, sudorese, tremor, vocalização, exploração, condutas desorganizadas, entre outras.

A presença de um cão no hospital para se recuperar de cetoacidose diabética chega em média a uma semana (DUARTE, 2015). Segundo Sousa e Rabelo (2015) "O ambiente de UTI pode ser altamente estressante para o paciente, que permanece afastado de seus tutores, em um local ruidoso e muito iluminado". Além disso, seu ciclo de sono é frequentemente interrompido, como nos horários de administração de medicamentos ou monitoração, sendo muitas vezes submetido à práticas invasivas e dolorosas.

Os estudos de comportamento são relevantes quando é necessário conduzir os animais de um lugar para outro através de corredores, rampas acima, para dentro de veículos ou de espaços estranhos a eles (GRANDIN; JOHNSON 2010). A redução do estresse é fator importante para o conforto do paciente. Estresse crônico por ambientes inadequados com pouco espaço e sem estímulos sensoriais apropriados (p. ex: cães que permanecem em locais sem visibilidade das pessoas e outros animais) pode afetar a saúde, o comportamento e qualidade de vida do 
animal (MALDONADO; GARCIA, 2015). Portanto, no ambiente em que os animais se encontram, inclusive o hospitalar, devem ser reconhecidos os fatores que causam estresse e/ou que impedem a expressão do comportamento natural, como barreiras físicas, o isolamento e a superlotação.

Neste sentido, é fundamental as avaliações da arquitetura das instalações, dos materiais de construção e de acabamento utilizados (tipo de pisos, paredes, portas, janelas, tetos); do espaço disponível e da maneira como é utilizado pelos animais, além das condições climáticas, tanto no ambiente interno como no externo (vento, correntes de ar, qualidade do ar, odores etc.) (MALDONADO; GARCIA, 2015). Esses autores elaboraram lista de regras e vantagens de um programa de bem-estar na clínica de pequenos animais:

- "Assegurar que todos os pacientes recebam os melhores cuidados;

- Assegurar que se aproveitem e se utilizem da melhor maneira os recursos humanos e as instalações da clínica;

- Fazer com que os clientes enfrentem menos crises, detectando precocemente os problemas comportamentais e sanitários dos seus animais;

- Garantir que os pacientes desfrutem de uma vida mais sadia e longa, o que poderia implicar para o clínico maior benefício expresso em visitas e utilização dos serviços da clínica;

- Estimular que os funcionários se sintam mais orgulhosos, comprometidos e satisfeitos com seu trabalho;

- Incentivar os tutores e a comunidade em geral a incrementar seus contatos educativos com a clínica (p.ex., aulas para socialização de filhotes e comunicação animal, controle do comportamento, educação básica e entretenimento, controle da reprodução, profilaxia e prevenção de enfermidades infecciosas e parasitárias, bem-estar nutricional e saúde oral)".

Avaliação do bem-estar do cão no hospital

Um dos desafios da Medicina Veterinária moderna é de conseguir definir parâmetros e métodos que permitam a avaliação do bem-estar de cães e gatos durante 0 atendimento e a internação hospitalar. Segundo Maldonado e Garcia (2015), existem uma série de fatores relacionados com o ser humano, o ambiente e o próprio animal que favorecem a identificação de variáveis e parâmetros para a avaliação objetiva ou por inferência do estado de bem-estar de um animal ou grupo de animais. A espécie, a raça, o sexo e a idade são fatores importantes para a avaliação do bem-estar em virtude das diferenças de comportamento, fisiologia e necessidades.

A habilidade e sensibilidade para identificar sinais físicos ou comportamentais que afetem o bem-estar do animal são qualidades essenciais para a manutenção ou melhoria da sua qualidade de vida. Há indicadores clínicos utilizados na avaliação do bem-estar animal, como fisiológicos (frequência respiratória, cardíaca e a temperatura), os bioquímicos (enzimas e hormônios relacionados com o estresse), e os imunológicos relacionados com a enfermidade, as lesões e a dor (provas paraclínicas) (MALDONADO; GARCIA, 2015).

Indicadores comportamentais são obtidos mediante registros observacionais e inventários comportamentais, como catálogos e etogramas. Também podem ser registrados por meio dos testes psicológicos, especialmente os testes de preferência (escolha) com análise da motivação (esforço que um animal faria para obter um estímulo positivo ou evitar os negativos) e o diagnóstico de anomalias de condutas (etopatias, psicopatias, sociopatias), sendo uma das mais estudadas a conduta 
estereotipada (MALDONADO; GARCIA, 2015).

A União Europeia publicou em 2009 o Welfare Quality Project que criou protocolos para avaliação de bem-estar de diversas espécies de animais de produção (WELFARE QUALITY, 2009), utilizando como pilar as "Cinco Liberdades" (FARM ANIMAL WELFARE COUNCIL, 2015), todavia há pouca informação semelhante para animais de companhia. Tendo como base as experiências com animais de produção, Maldonado e Garcia (2015) propuseram a avaliação para cães e gatos relacionada à quatro parâmetros, a saber:

1. Boa Nutrição: os animais estão sendo alimentados e supridos apropriadamente com alimento e água?

2. Bom alojamento: os animais estão alojados adequadamente?

3. Boa Saúde: os animais estão saudáveis?

4. Comportamento apropriado: o comportamento dos animais reflete um estado emocional positivo?

Naturalmente que nos hospitais os animais não estão gozando de boa saúde, mas a partir destes pontos é possível avaliar se os recintos da internação são adequados à espécie, se a iluminação é apropriada, se os pacientes cães e gatos conseguem expressar corretamente alguns de seus comportamentos naturais, como caminhar e se esconder, e se estão sofrendo de estresse. Pesquisa da Universidade de Copenhagen de acompanhamento de tratamentos veterinários de cães e de gatos, fazendo referência aos termos "bem-estar animal", "qualidade de vida" ou "bem-estar", revelou a dificuldade de avaliação correta desta realidade (CHRISTIANSEN; FORKMAN, 2007).

Veterinários e tutores não têm exatamente os conhecimentos necessários para a avaliação etológica do bem-estar animal em um sentido mais amplo. $O$ desenvolvimento e a validação de parâmetros e instrumentos de avaliação de bemestar animal em um contexto veterinário é necessário e poderia se beneficiar da especialização, experiência e posição mais imparcial dos etólogos (CHRISTIANSEN; FORKMAN, 2007).

Yeates (2013) reforça que a avaliação do bem-estar do animal deve ser feita com informações do veterinário, do tutor e até dos enfermeiros que lidam com o animal. Nem sempre tais avaliações vão coincidir. O primeiro passo é levantar "o que é importante para o animal" e "o que é importante para a avaliação de seu bemestar". É preciso fazer um histórico do paciente e avaliação clínica detalhada, esses dados serão acompanhados dia a dia. Sobretudo, deve-se levar em consideração que "tratamentos afetam o bem-estar do animal de muitas maneiras, encobrem ou não sintomas, e até arrefecem sentimentos". No caso de pacientes com doença terminal, o autor sugere um questionário específico sobre bem-estar que considera a qualidade de vida, a duração da vida e as opções de tratamento.

A avaliação do bem-estar pode ser realizada de maneira objetiva. Taxa de mortalidade, sucesso reprodutivo, extensão da atividade adrenal, quantidade de comportamento anormal, severidade de ferimentos, grau de imunossupressão ou nível de incidência de doenças podem ser medidos (BROOM; FRASER, 2015).

Desta forma, é preciso conhecer os etogramas dos cães, que são o inventário completo e a descrição exata de todos os tipos de comportamentos das espécies, bem como a ontogenia ou desenvolvimento dos seus comportamentos, seus métodos de comunicação e organização social para o entendimento dos processos de estresse, infelicidade e doença, e para recomendar as modificações necessárias para que a qualidade de vida do animal seja melhorada (BROOM; FRASER, 2015). 


\section{Estresse}

A avaliação correta de estresse e de distresse (estresse excessivo e nocivo) e de suas consequências na prática veterinária é fundamental para melhorar o bemestar do paciente. O estresse foi inicialmente descrito em 1936 pelo cientista Hans Seyle como "a síndrome geral de adaptação", na tentativa de compreender o desequilíbrio da homeostase no organismo. A síndrome pode sofrer variações dependendo do tipo de estressor, da duração e da intensidade (SEYLE, 1956). A palavra "estressor" é empregada em sentido de ação danosa, para distinguir-se de "estresse", que pode "ser positivo e bom" em iniciativas a favor da vida (THE AMERICAN INSTITUTE OF STRESS, 2015).

Segundo Seyle (1956) a síndrome tem três fases. Inicia-se na fase de alarme, quando ocorre o reconhecimento da situação estressora pelo sistema nervoso central. O animal responderá com a ação de "luta e fuga", descrita por Cannon em 1929 e citada por Maria e Maiorka (2015). Ao primeiro sinal de ameaça, a informação é processada pelo hipotálamo, que irá ativar o sistema nervoso autônomo simpático e o eixo simpático adreno-medular, com subsequente ativação do eixo hipotálamo-pituitária-adrenal (HPA). Com a ativação do sistema nervoso autônomo, diversos parâmetros fisiológicos serão alterados por meio da secreção de catecolaminas da medula adrenal e dos terminais nervosos noradrenérgicos, como aumento da frequência, débito e contração cardíaca, secreção de glândulas exócrinas, vasoconstrição periférica, glicogenólise e gliconeogênese, entre outros (SEYLE, 1956). Essas alterações preparam o organismo para agir rapidamente mediante situações estressoras (PACAK; McCARTY, 2007).

Depois de iniciada a situação estressora, os animais começam a apresentar, entre seis e 48 horas, aumento considerável do córtex adrenal, em resposta à liberação de hormônio adrenocorticotrófico (ACTH) pela ativação do eixo HPA; atrofia de órgãos linfoides, como timo, baço e linfonodos; úlceras gástricas e duodenais; perda dos lipídios da cortical e substância cromafim da adrenal; acúmulo de transudato pleural e peritoneal; perda do tônus muscular; queda da temperatura corporal; hiperemia cutânea; exoftalmia; aumento da produção de lágrimas e saliva; e, em alguns casos, observa-se necrose focal do fígado (SEYLE, 1956, e PACAK; McCARTY, 2007).

Se o organismo continuar sendo exposto a qualquer agente nocivo capaz de provocar a reação de alarme, inicia-se a fase de resistência. Nesta, a adrenal apresenta-se aumentada, com recuperação dos grânulos lipídicos da cortical e vacuolização das células cromafins da medula [...]. É nesta fase que se observam alterações no crescimento, na reprodução e no sistema imunológico (MARIA; MAIORKA, 2015).

Nos casos em que o estímulo estressor permanece com a mesma intensidade por um longo período, o organismo não consegue mais se manter estável e começa a apresentar diversas alterações; caso esse estímulo estressor não seja removido a tempo, pode levar ao óbito. Os sintomas nessa fase são similares aos da fase de alarme, porém mais intensos, determinando a terceira e última fase, conhecida como fase de exaustão. Nesta fase, a depleção dos estoques energéticos é acentuada pela atividade do eixo HPA e pelo início das mudanças fisiopatológicas nos sistemas imunológico e gastroentérico, com imunossupressão grave e úlceras. O desenvolvimento de doenças crônicas como diabetes e hipertensão e distúrbios comportamentais podem ocorrer. Nenhum organismo consegue permanecer por muito tempo na fase de alarme: ou passa para a fase de resistência, ou vai a óbito (SELYE, 1956). 
Os estressores podem ser agrupados com base em suas características, duração e intensidade. Em relação à duração, estes são agudos ou crônicos; podem ser físicos, biológicos, químicos, psicológicos e sociais. Dentre os físicos, pode-se destacar frio, calor, barulho. Os químicos integram diversos tipos de medicamentos, venenos etc. $O$ estresse psicológico interage com o comportamento do indivíduo e altera a sua reação à ansiedade, ao medo e à frustração. Já o estresse social está relacionado com a dominância entre animais de um grupo, a introdução de novos indivíduos ou até a transferência para um local desconhecido (PACAK; McCARTY, 2007).

$\mathrm{Na}$ prática veterinária, deve-se levar em consideração que o estresse por separação é comum em cães. Os laços são tão estreitos entre cães e seus tutores que é comum a ansiedade por separação por parte do animal. Em angústia de separação, os cães, podem apresentar diversos comportamentos, andam de um lado para outro, gemem e arquejam, além de latir ou uivar alto, urinam, defecam e mastigam. Este tipo de transtorno pode chegar a $20 \%$ do total da população de cães. No Reino Unido estes chegariam a cerca de 1,5 milhão os cães com ansiedade de separação (BRADSHAW, 2012).

A World Small Animal Veterinary Association (WSAVA) elaborou um projeto, a partir da colaboração de pesquisadores de vários países, para padronizar os exames dos pacientes a partir dos cinco sinais vitais. Os cinco sinais vitais sugeridos são temperatura, pulso, respiração, avaliação da dor e avaliação nutricional. Segundo o documento, essa avaliação e as recomendações para o cuidado com animais de pequeno porte ajudam a desenvolver uma parceria entre o tutor e o veterinário (FREEMAN et al., 2011)

Em relação aos cuidados nutricionais, incluiu-se a necessidade de providenciar alimentação variada e habitual para os pacientes hospitalizados, pequenas mudanças como o aquecimento da comida, levar o animal a uma área tranquila para alimentação e fazer com que o tutor alimente o animal, podem aumentar a ingestão de alimentos pelo paciente (FREEMAN et al., 2011). O suporte nutricional como fator independente influencia o prognóstico e deve ser considerado parte integral do tratamento do paciente crítico.

\section{O hormônio ocitocina}

A importância dos vínculos e a relação do hormônio ocitocina vem sendo estudados há muitos anos (CHEN; SATO, 2017), tendo sido evidenciada na relação cão-tutor em estudos de NAGASAWA e colaboradores (2015). Segundo os autores, quando os cães e os seres humanos olham nos olhos um dos outros, ambos experimentam um aumento da ocitocina, um hormônio que tem sido associado à confiança e ao vínculo materno. O mesmo aumento da ocitocina ocorre quando as mães e bebês humanos olham uns para os outros, o que sugere que os cães podem ter adquirido essa resposta para uma melhor ligação com a nova família humana (GRIMM, 2015).

A ação mais bem conhecida da ocitocina é o reflexo de liberação do leite materno. Na fêmea lactante, estímulos tácteis e visuais associados à sucção ou ordenha induzem a liberação de ocitocina na corrente circulatória (CHEN et al., 2017). A ocitocina desempenha um papel primário na regulação do estabelecimento de vínculo social entre a mãe e seus filhos, e entre parceiros sexuais em espécies monogâmicas. Além disso, a ativação dos sistemas de ocitocina aumenta a recompensa social e inibe a atividade do eixo hipotalâmico-pituitário-adrenal induzida pelo estresse (NAGASAWA et al., 2015). 
Segundo Mitsui e colaboradores (2011) a interação tátil entre humanos e cães aumenta as concentrações periféricas de ocitocina, em ambos. Esses resultados foram corroborados no estudo de Nagasawa et al. (2015) que sustentam a existência de um ciclo positivo mediado por ocitocina que se auto perpetua nas relações entre humanos e cães, ciclo que é similar àquele das relações entre mães humanas e seus filhos. A interação entre humanos e cães, através do comportamento do tipo humano de contemplar, trouxe efeitos de recompensa social, devido à liberação de ocitocina, tanto nos humanos como nos cães, e estimulou o aprofundamento das relações mútuas, que levou ao estabelecimento do vínculo entre espécies. Além disso, a ocitocina administrada por via nasal, aumentou o comportamento de contemplação nos cães, o que por sua vez elevou a concentração urinária de ocitocina nos tutores. Estas descobertas sustentam a existência de um ciclo positivo interespecífico, mediado pela ocitocina (NAGASAWA et al., 2015).

Cães são mais habilidosos do que lobos e chimpanzés, os parentes mais próximos, respectivamente, de cães e de humanos, ao utilizarem comportamentos de comunicação social humanos. Mais especificamente, cães são capazes de utilizar a mútua contemplação como ferramenta de comunicação (HARE; TOMASELLO, 2005).

De forma semelhante, estudos anteriores já indicavam a relação da ocitocina com a formação de vínculos. Em humanos "a contemplação mútua" é a mais fundamental manifestação de vínculo social entre uma mãe e seu filho, e a ocitocina materna está associada de maneira positiva com a duração da contemplação entre mãe e filho (DICKSTEIN et al., 1984).

\section{Ciclo Circadiano}

Ciclos de luz e temperatura são provavelmente os dois instrumentais que fornecem percepção de tempo confiáveis para os sistemas vivos na Terra. Como consequência, os organismos utilizam esses sinais para ajustar os seus ritmos circadianos endógenos ao dia solar (BUHR et al., 2010). A temperatura é um agente de ajustamento primordial para os ritmos circadianos em todos os organismos [mamíferos] com a exceção de vertebrados homeotérmicas (BUHR et al., 2010).

A iluminação é ponto chave para o bem-estar de mamíferos. O hormônio melatonina produzido está ligado a este relógio biológico: a menor incidência de luz provoca a produção do hormônio que induz ao sono (WEBB et al., 2014).

Quando o sol se põe e a escuridão ocorre, a glândula pineal é estimulada pelo SCN e começa a produzir ativamente melatonina, que é liberada no sangue. Níveis de melatonina durante o dia são dificilmente detectável. Para além de ajustar o calendário do relógio, luz brilhante tem um outro efeito. Esta inibe diretamente a liberação de melatonina (SINGH;JADHAV, 2014; KAPPEN et al. 2014).

A melatonina ( $\mathrm{N}$-acetil-5-metoxitriptamina) é sintetizada pela glândula pineal. As células do parênquima pineal captam o aminoácido triptofano da circulação e o convertem em serotonina. Duas etapas do metabolismo da serotonina estão sob controle neural. A primeira é a conversão da serotonina em $\mathrm{N}$-acetil-serotonina, que depois é convertida em melatonina. A segunda etapa envolve a enzima formadora de melatonina, hidroxiindol-O-metil-transferase. A síntese e a secreção de melatonina são controladas pelo ciclo (WEBB et al., 2014).

O sistema de relógio circadiano em mamíferos compreende estimuladores endógenos localizados no cérebro e na periferia que organizam várias atividades biológicas, incluindo o comportamento, o humor, a memória, metabolismo, 
temperatura corporal, a atividade neural, hormonal. O núcleo supraquiasmático (SCN) no hipotálamo é o principal regulador dos relógios biológicos. Assim, os relógios são sincronizados por fatores ambientais, incluindo ciclos de luz-escuro, comida, exercício e drogas (TAHARA et al., 2015; NAKAMURA et al., 2016). Sendo assim, de fundamental importância para o bem-estar de animais internados 0 respeito a esses ciclos biológicos.

\section{CONSIDERAÇÕES FINAIS}

A Medicina Veterinária dispõe de pesquisas científicas e experiências capazes de garantir novo estágio de bem-estar aos pacientes caninos e felinos no atendimento e na internação hospitalar. Na atualidade, os cães estão cada vez mais integrados às famílias humanas o que faz com que os argumentos a favor de propostas de bem-estar sejam igualmente de base econômica.

Conhecer e atender as Liberdades, Oportunidades e Necessidades dos animais podem ser asseguradas na condição de pacientes no contexto hospitalar. No caso de doenças crônicas, endócrinas, da geriatria, na recuperação de cirurgias e traumas, o avanço possível é expressivo.

Diante da revisão de literatura apresentada, pode-se afirmar que o bem-estar do paciente deve ser o princípio base de todo o tratamento, e não apenas um complemento. Tratar cães considerando suas origens, natureza, aspectos biológicos, seus sentimentos e a importante relação com seu tutor é condição imperativa para maior sucesso da terapia.

O bem-estar como pilar da prática veterinária de pequenos animais é uma tendência mundial, tendo já importante suporte científico e atende expectativas e demandas de todos os envolvidos, especialmente, paciente e tutor.

\section{REFERÊNCIAS}

ANIMAL WELFARE ACT. Promotion of welfare. 2006. UK. Disponível em: $<$ http://www.legislation.gov.uk/ukpga/2006/45/crossheading/promotion-of-welfare>. Acesso em: 15 nov. 2015.

AXELSSON E.; RATNAKUMAR A.; ARENDT M.; MAQBOOL, K.; WEBSTER M.; PERLOSKI M.; LIBERG O.; ARNEMO J.M.; HEDHAMMAR A.; LINDBLAD-TOH K. The genomic signature of dog domestication reveals adaptation to a starch-rich diet. Nature, v.495, p360-364, 2013. Disponível em: https://insights.ovid.com/nature/natr/2013/03/210/genomic-signature-dogdomestication-reveals/67/00006056. DOI: 10.1038/nature11837

BRADSHAW, J. Cão senso. Rio de Janeiro: Record, p. 6-18, 2012.

BROOM, D.M. Indicators of poor welfare. The British Veterinary Journal, v.142, n.6, p.524-526, 1986. Disponível em <http://endcap.eu/wpcontent/uploads/2015/06/Broom-1986-Indicators-of-poor-animal-welfare.pdf>. DOI: 10.1016/0007-1935(86)90109-0

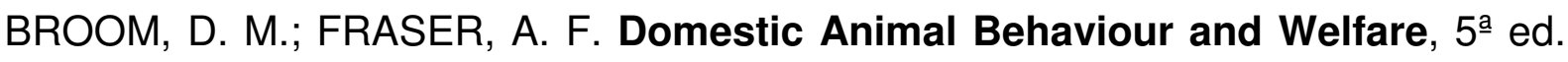
London: Cabi, 472p. 2015.

BUHR, E.; YOO, S.; TAKAHASHI, J.S. Temperature as a universal resetting cue for mammalian circadian oscillators. Science, v. 330, p. 379-384, 2010. Disponível em: 
CHEN, S.; SATO, S. Role of oxytocin in improving the welfare of farm animals - A review. Asian-Australasian Journal of Animal Sciences. v.30, 4, p.449-454, 2017. Disponível em: < https://www.ncbi.nlm.nih.gov/pmc/articles/PMC5394829/>. DOI: $10.5713 \% 2 F a j a s .15 .1058$

CHEN S.; ROH S.; SATO S.; OGURA S. Relationship of Serum Oxytocin Concentration to Positive Social Behaviors in Cattle. Journal of Integrated Field Science, v.14, p. 14-21, 2017. Disponível em: < https://tohoku.repo.nii.ac.jp/?action=repository_action_common_download\&item_id= 123806\&item_no=1\&attribute_id=18\&file_no=1>. DOI: 10.5713/ajas.15.1058.

CHRISTIANSEN, S. B.; FORKMAN, B. Assessment of animal welfare in a veterinary context - A call for ethologists. Journal Applied Animal Behaviour, v. 106, n.4, p. 203-220, 2007. Disponível em: <http://curis.ku.dk/ws/files/22953246/AssessmentOfAnimalWelfare.pdf>. $\quad$ DOI: 10.1016/j.applanim.2007.01.004

DARWIN, C. A Expressão das Emoções no Homem e nos Animais (título original The Expression of the Emotions in Man and Animals). São Paulo: Companhia das Letras. 2000.

DARWIN, C. A Origem das Espécies e a Seleção Natural (título original The Origin of Species by Means of Natural Selection). São Paulo: Madras, 2011, p. 70.

DARWIN, C. The variation of animals and plants under domestication. London: John Murray, 2d edition, vol. 1, 1875.

DICKSTEIN, S.; THOMPSON, R.A.; ESTES, D.; MALKIN C.; LAMB, M.E. Social referencing and the security of attachment. Infant Behavior and Development, 7, p. 507-516, $1984 . \quad$ Disponível em: <https://deepblue.lib.umich.edu/handle/2027.42/24687>. DOI: 10.1016/S01636383(84)80009-0

DUARTE, R. Cetoacidose Diabética. In: JERICÓ, M. M.; NETO, J.P. de A.; KOGIKA, M. M. Tratado de Medicina Interna de Cães e Gatos. Rio de Janeiro: Roca, v. 2, p. 1764-1765, 2015.

FARM ANIMAL WELFARE COUNCIL. Disponível em: http://webarchive.nationalarchives.gov.uk/20121007104210/http://www.fawc.org.uk/fr eedoms.htm. Acesso em: 10 set 2017.

FAVARO, A. B. B. B. DA C.; COSTA, R.V.; MARTINS, C.M.; BIONDO, A.W. IBGE realiza a primeira pesquisa amostral da população de cães e gatos do Brasil. Clínica Veterinária, Ano XX, n. 118, setembro/outubro, p. 42-45, 2015. Disponível em: http://www.revistaclinicaveterinaria.com.br/edicao/2015/setembro-outubro.html 
FREEMAN, L.; BECVAROVA, I.; CAVE, N.; MACKAY, C.; NGUYEN, P.; RAMA, B.; TAKASHIMA, G.; TIFFIN, R.; TSJIMOTO, H.; VAN BEUKELEN, P. WSAVA Nutritional Assessment Guidelines. Journal of Small Animal Practice, v.52, n.4, p. 385-396. 2011. Disponível em: http://onlinelibrary.wiley.com/doi/10.1111/j.17485827.2011.01079.x/full. DOI:10.1111/j.1748-5827.2011.01079.x

GRANDIN, T.; JOHNSON, C. O Bem-Estar dos Animais - Proposta de uma vida melhor para todos os bichos, Rio de Janeiro: Rocco, 2010.

GRIMM, D. Dawn of the Dog. Science. v. 348, n.6232, p. 274, 2015. Disponível em: <http://science.sciencemag.org/content/348/6232/274>.

DOI: 10.1126/science.348.6232.274.

HARE, B., TOMASELLO, M. Human-like social skills in dogs?. Trends in Cognitive Sciences. $\quad$ v.9, p. 439-444, 2005. Disponível em: < https://chd.ucsd.edu/_files/winter2009/hare.tomasello.dogs.2005.pdf>. DOI: 10.1016/j.tics.2005.07.003

HARRISON, R. Animal Machines:The New Factory Farming Industry. London: Vincent Stuart, 1964.

HARRISON, R. Animal Machines. Foreword by Rachel Carson and new contributions from: Marian Stamp Dawkins, John Webster, Bernard E. Rollin, David Fraser and Donald M. Broom. UK: CABI, 2013.

IBGE. Pesquisa Nacional de Saúde 2013. Disponível em: http://www.ibge.gov.br/home/estatistica/populacao/pns/2013_vol2/default.shtm.

Acesso em 11 de set. 2015.

JERICÓ, M. M.; NETO, J.P. A.; KOGIKA, M. M. Tratado de Medicina Interna de Cães e Gatos, v. 1 e 2, Rio de Janeiro: Roca, 2015.

KAPPEN, K. L.; GARNER, L. M.; KERR, K. R.; SWANSON, K. S. Effects of photoperiod on food intake, activity and metabolic rate in adult neutered male cats. Journal of animal physiology and animal nutrition, v.98, n.5, p.958-967, 2014. Disponível em: <http://onlinelibrary.wiley.com/doi/10.1111/jpn.12147/full.> DOI: 958967. 10.1111/jpn.12147

MALDONADO, N. A. C.; GARCIA, R. C. M. Bem-estar Animal. In: Tratado de Medicina Interna de Cães e Gatos, JERICÓ, M. M.; NETO, J.P. de A.; KOGIKA, M.M. v. 2, Rio de Janeiro: Roca, 2015., p. 2282 e 2285.

MARIA, A. C. B. E.; MAIORKA, P. C. Estresse e Síndrome Geral de Adaptação. In: JERICÓ, M. M.; NETO, J.P. de A.; KOGIKA, M. M. Tratado de Medicina Interna de Cães e Gatos, v 2, Rio de Janeiro: Roca, 2015, p. 2293.

McMILLAN, F. D. Mental health and well-being in animals. Boston: Blackweell Publishing, 2005.

MELLOR, D.J.; BEUSOLEIL, N.J. Extending the Five Domains model for animal 
welfare assessment to incorporate positive welfare states. Animals Welfare, v. 24, p. 2015.

Disponível em: http://www.ingentaconnect.com/content/ufaw/aw/2015/00000024/00000003/art0000. DOI: 10.7120/09627286.24.3.241

MITSUI, S.; YAMAMOTO, M.; NAGASAWA, M.; MOGI, K.; KIKUSUI , T.; OHTANI, N.; OHTA, M. Urinary oxytocin as a noninvasive biomarker of positive emotion in dogs. Hormones and Behavior, v.6, p.125-136, 2011. Disponível em: < http://www.sciencedirect.com/science/article/pii/S0018506X11001322>. DOI: 10.1016/j.yhbeh.2011.05.012

NAGASAWA, M.; MITSUI, S.; EN, S.; OHTANI, S.; OHTA, M.; SAKUMA, Y.; ONAKA, T.; MOGI, K.; KIKUSUI, T. Oxytocin-gaze positive loop and the coevolution of human-dog bonds. Science, v. 348, n.6232, p. 333-336, 2015. Disponível em: < http://science.sciencemag.org/content/348/6232/333>.DOI:

$10.1126 /$ science. 1261022

NAKAMURA, T.J.; TAKASU, N.N; NAKAMURA, W. J. The suprachiasmatic nucleus: age-related decline in biological rhythms. Physiology Science, v.66, p. 367- 374, 2016. Disponível em: https://link.springer.com/article/10.1007/s12576-016-04392\#citeas. DOI: 10.1007/s12576-016-0439-2

PACAK, K.; McCARTY, R. Acute stress response: experimental. In: Fink G, editor. Encyclopedia of stress. San Diego: Academic Press, 2007.

SELYE, H. A. Stress of life. New York: McGraw-Hill, 1956.

SINGH, M.; JADHAV, H.R. Melatonin: functions and ligands. Drug discovery today, v. 19, n. $9, \quad$ p. 1410-1418, $2014 . \quad$ Disponível em:<http://www.sciencedirect.com/science/article/pii/S1359644614001512>.

DOI:10.1016/j.drudis.2014.04.014

SKOGLUND, P.; ERSMARK, E.; PALKOPOULOU, E.; DALE'N, L. Ancient Wolf Genome Reveals an Early Divergence of Domestic Dog Ancestors and Admixture into High-Latitude Breeds. Current Biology, v. 25, n.11, p.1515 -1519,2015. Disponível em: < https://ac.els-cdn.com/S0960982215004327/1-s2.0S0960982215004327-main.pdf? tid=bb09a12c-a70f-11e7-87fa00000aacb360\&acdnat $=1506907346 \_$eb0d6551ea645d89dfcc23b537b4bbd6> DOI: 10.1016/j.cub.2015.04.019 
SOUSA, A. A.; RABELO, C. R. Reabilitação no Paciente Grave. In: JERICÓ, M. M.; NETO, J.P. de A.; KOGIKA, M. M. Tratado de Medicina Interna de Cães e Gatos, v 1, Rio de Janeiro: Roca, 2015, p. 97.

TAHARA, Y.; SHIRAISHI, T.; KIKUCHI, Y.; HARAGUCHI, A.; KURIKI, D.; SASAKI, H.; MOTOHASHI, H.; SAKAI, T.; SHIBATA, S. Entrainment of the mouse circadian clock by sub-acute physical and psychological stress. Scientific Reports Nature. p. 1-2, 2015. Disponível em: < https://www.nature.com/articles/srep11417?messageglobal=remove\&WT.ec_id=SREP-63120150616\&spMailingID=48887634\&spUserID=ODkwMTM2NjQzMAS2\&spJobID=70 2065282\&spReportld=NzAyMDY1MjgyS0\#additional-information>.

$\mathrm{DOI}$ 10.1038/srep11417.

THE AMERICAN INSTITUTE OF STRESS. What is stress? Disponivel em: http://www.stress.org/what-is-stress. Acesso em: 6 de novembro 2015.

WEBB, I. C.; ANTLE, M. C. MISTLBERGER, R. E. Regulation of circadian rhythms in mammals by behavioral arousal. Behavioral Neuroscience, v.128, p.304 -325, 2014. Disponível em: <http://www.apa.org/pubs/journals/special/2052803.aspx>. DOI:10.1037/a0035885.

WELFARE QUALITY®, 2009. Welfare Quality ${ }^{\circledR}$ Assessment Protocol for Cattle. Welfare Quality® Consortium, Lelystad, Netherlands.

YEATES, J. Animal Welfare in Veterinary Practice. UK: Wiley-Blackwell, 2013. 